IOS Press

\title{
Review
}

\section{Challenges and Considerations Related to Studying Dementia in Blacks/African Americans}

\author{
Eseosa T. Ighodaro ${ }^{\mathrm{a}, \mathrm{b}, *}$, Peter T. Nelson ${ }^{\mathrm{a}, \mathrm{b}, \mathrm{c}, *}$, Walter A. Kukull ${ }^{\mathrm{d}}$, Frederick A. Schmitt ${ }^{\mathrm{b}, \mathrm{e}}$, \\ Erin L. Abner ${ }^{\mathrm{b}, \mathrm{f}}$, Allison Caban-Holt ${ }^{\mathrm{b}, \mathrm{g}}$, Shoshana H. Bardach ${ }^{\mathrm{b}, \mathrm{g}}$, Derrick C. Hord ${ }^{\mathrm{b}}$, \\ Crystal M. Glover ${ }^{\mathrm{h}}$, Gregory A. Jicha ${ }^{\mathrm{b}, \mathrm{e}}$, Linda J. Van Eldik ${ }^{\mathrm{a}, \mathrm{b}}$, Alexander X. Byrd ${ }^{\mathrm{i}}$ \\ and Anita Fernander ${ }^{j}$ \\ ${ }^{a}$ Department of Neuroscience, University of Kentucky, Lexington, KY, USA \\ ${ }^{\mathrm{b}}$ Sanders-Brown Center on Aging, University of Kentucky, Lexington, KX, USA \\ ${ }^{\mathrm{c}}$ Department of Pathology and Laboratory Medicine, Division of Neuropathology, University of Kentucky, \\ Lexington, $K Y, U S A$ \\ ${ }^{\mathrm{d}}$ National Alzheimer's Coordinating Center, Department of Epidemiology, University of Washington, \\ Seattle, WA, USA \\ ${ }^{\mathrm{e}}$ Department of Neurology, University of Kentucky, Lexington, KY, USA \\ ${ }^{\mathrm{f}}$ Department of Epidemiology, University of Kentucky, Lexington, $K Y, U S A$ \\ ${ }^{\mathrm{g}}$ Graduate Center for Gerontology, University of Kentucky, Lexington, KY, USA \\ ${ }^{\mathrm{h}}$ Rush Alzheimer's Disease Center, Rush University Medical Center, Chicago, IL, USA \\ ${ }^{\mathrm{i}}$ Department of History, Rice University, Houston, Texas, USA \\ ${ }^{\mathrm{j}}$ Department of Behavioral Science, University of Kentucky, Lexington, KY, USA
}

Accepted 26 June 2017

\begin{abstract}
Blacks/African Americans have been reported to be 2-4 times more likely to develop clinical Alzheimer's disease (AD) compared to Whites. Unfortunately, study design challenges (e.g., recruitment bias), racism, mistrust of healthcare providers and biomedical researchers, confounders related to socioeconomic status, and other sources of bias are often ignored when interpreting differences in human subjects categorized by race. Failure to account for these factors can lead to misinterpretation of results, reification of race as biology, discrimination, and missed or delayed diagnoses. Here we provide a selected historical background, discuss challenges, present opportunities, and suggest considerations for studying health outcomes among racial/ethnic groups. We encourage neuroscientists to consider shifting away from using biologic determination to interpret data, and work instead toward a paradigm of incorporating both biological and socio-environmental factors known to affect health outcomes with the goal of understanding and improving dementia treatments for Blacks/African Americans and other underserved populations.
\end{abstract}

Keywords: Autopsy, epidemiology, ethnicity, neurodegenerative, neuropathology

\footnotetext{
${ }^{*}$ Correspondence to: Eseosa T. Ighodaro, PhD, Department of Neuroscience, Sanders-Brown Center on Aging, University of Kentucky, Sanders-Brown Center on Aging Building, 800 South Limestone, Lexington, KY 40536-0230, USA. Tel.: +1 859218 2396; E-mail: etigho2@uky.edu and Peter T. Nelson,
}

\footnotetext{
MD, PhD, Department of Pathology, Division of Neuropathology, Sanders-Brown Center on Aging, University of Kentucky, Sanders-Brown Center on Aging Building, 800 South Limestone, Lexington, KY 40536-0230, USA. Tel.: +1 859218 5038; E-mail: pnels2@uky.edu.
} 


\section{INTRODUCTION}

Studying dementia across racial/ethnic populations is a controversial but important area of research. Findings from clinical studies have indicated that Blacks/African Americans are more likely to develop Alzheimer's disease (AD, a major cause of dementia) in comparison to Caucasians (hereafter referred to as Whites) [1-3]. In studies that include autopsy confirmation, the outcomes are less clear: Blacks/African Americans may develop more $\mathrm{AD}$ and/or mixed pathologies than Whites $[4,5]$; however, other studies found either no $\mathrm{AD}$ pathological differences between Blacks/African Americans and Whites [6-9] or higher burden of $\mathrm{AD}$ pathology in Whites in comparison to Blacks/African Americans [10]. Reasons for differences in the studies' outcomes may be attributable partly to residual confounding related to a failure to take into account historical, cultural, political, sociological, and psychological factors that contribute to health outcomes. Perhaps most importantly, clinical research participation in historically marginalized groups (e.g., Blacks/African Americans) has influenced reported research outcomes.

With this commentary, it is our intention to help focus attention on achieving one of the National Institutes of Health (NIH) and the U.S. Department of Health \& Human Services (USDHS) objectives to "increase the availability and quality of data collected and reported on racial and ethnic minority populations" [11]. We outline a selected historical account of the relationship between Blacks/African Americans, medicine, and research, focusing on challenges and relevant factors that impact Black/African American participation in research. We conclude with considerations and topical questions for neuroscientists with a focus on research related to dementia in Blacks/African Americans.

Note on terminology: Hereafter, we apply racial categorical terminologies described in the 1997 "Revisions to the Standards for the Classification of Federal Data on Race and Ethnicity" issued by Office of Management and Budget's (OMB): "Black/ African American" and "White." For complete definitions, see reference [12].

\section{The contemporary consequences of historical medical mistreatment of Blacks/African Americans}

There is a long history of horrific biomedical experimentation on Blacks/African Americans and the effects linger to this day. A selection of examples are discussed here for three reasons: 1) to convey that late 19th century/early 20th century scientists designed abusive studies which grossly violate the concept of primum non nocere ("first, do no harm"); 2) to provide examples on the dangers of misinterpreting differences between individuals within different racial/ethnic groups; and 3) to demonstrate how the history of racism in the medical sciences and society affect current Black/African American participation in clinical research. Nineteenth and early 20 th century scientists developed analytical methodologies that lay the foundation for how we conduct 21 st century science. Therefore, the history highlights methodological pitfalls that are topical and highly relevant to the contemporary setting.

Before the U.S. Civil War, African slaves were regularly used as involuntary test subjects in biomedical experimentations [13, 14], and these practices were supported by law [15]. Often, slave masters offered their slaves to physicians either for biomedical experimentation or because the slaves were either too sick or old, or in exchange for medical treatment payment [13]. In addition, some physicians would buy and raise slaves in order to fill their studies with human test subjects $[13,15]$. The practice of collecting slaves as research subjects was not an anomaly but a standard practice due to the mainstreaming of racism in much of American society, including science. Some writers use the term 'scientific racism' to describe this perversion of scientific and historical factors to maintain existing social hierarchies based on race [16, 17]. For example, it was believed that Blacks/African Americans could endure more painful stimuli, extreme heat, and were more prone to fevers, syphilis, tuberculosis, and tetanus than White individuals [15, 18]. These 19th and early 20th century scientists used this framework of racism to design flawed experiments that yielded results that further inappropriately justified their use of slaves in biomedical experimentation. For example, lacking a rational scientific reason, Dr. Walter F. Jones repeatedly poured boiling water on naked slaves in four-hour intervals to see if it cured typhoid pneumonia $[15,19,20]$. Dr. John M. B. Haden stripped blood vessels from the limbs of a Black/African American male in order to study vascular morphology [15, 21]. Dr. James M. Sims, "the father of gynecology," performed painful experimental gynecological surgery on female slaves without using anesthesia in order to improve his surgical techniques [13, 22, 23]. Dr. T.S. Hopkins gave 
nitric acid solutions to slaves in order to test its effects on treating asthma [13, 15]. Thomas Jefferson inoculated over 200 slaves with the cowpox vaccine in order to test its efficacy against smallpox $[15,20]$. These examples demonstrate how racialized science became part of the justification and practice of human experimentation on Blacks/African Americans [16].

After the abolition of slavery in the U.S., physicians and scientists continued to abuse Blacks/ African Americans while conducting unethical biomedical experimentation. One of the most wellknown unethical studies was the Tuskegee Syphilis Trials from 1932-1972 [15, 20, 24, 25]. Funded by the USDHHS, scientists withheld treatment from 400 Black/African American men in order to study the progression of syphilis. One goal of the study was to test the long-standing belief that venereal diseases manifested differently in Black/African American individuals compared to White individuals [15, 20, $24,25]$. In an article published in 1937, Dr. Mark Boyd describes conducting an experiment where he infected 470 syphilitic Black/African American individuals with a deadly falciparum strain in order to test new treatments for neurosyphilis $[15,26]$. Although some of the individuals died as a direct result from his procedure, he still continued to infect other Black/African American individuals [15, 26]. In 1952, Chester M. Southam of Sloan-Kettering Institute injected at least 396 inmates at the Ohio State Prison (more than $45 \%$ of the subjects were Black/African American) with live human cancer cells $[15,27]$. From 1962-1966, Dr. Allen Hornblum conducted over 153 experiments using mostly Black/African American men from the Philadelphia's Holmesburg Prison system [15, 28]. Hornblum was paid by pharmaceutical and cosmetic companies to test cosmetics, powders, and shampoos, some of which caused baldness, scarring, and permanent skin and nail injury in the prisoners [15, 28]. In 1978, without parental consent, physicians from the Medical College of Virginia injected 1,230 children $(37 \%$ were Black/African American children, 4 times their population representation during that period) with radioactive substances [15]. From 1993-1995, scientists from the Kennedy Krieger Institute (KKI) conducted research investigating lowcost partial lead abatement procedures in children living in Baltimore's public housing facilities [29]. As a result, families sued the KKI stating that they were not fully informed of the risks of their children's participation in the study [29]. In sum- mary, the physicians and scientists in these studies performed horrific and sometimes deadly experiments on many Black/African American individuals without regard for their informed consent or wellbeing. This is by no means an exhaustive list of all the unethical biomedical studies performed on Blacks/African Americans. The historic and presumed (by many) present practice of unethical research on Black/African American individuals constitute a primary reason for the distrust of physicians and scientists within the Black/African American community - a direct factor limiting their desire to participate in biomedical research [24, 30-33], among other factors. In a systematic review of barriers and facilitators to minority research participation, George et al. found that 77\% $(n=34)$ of the articles included in their analyses stated that "mistrust of the medical system" was a barrier for Black/African American participation in clinical human studies [33]. Using a national survey completed by 527 Blacks/African Americans and 382 Whites, CorbieSmith et al. reported that Blacks/African Americans, compared to Whites, were more likely to believe that they would be used as guinea pigs in biomedical experimentation without their consent $(79.2 \%$ versus $51.9 \%, p<0.01)[30]$.

Due to Blacks'/African Americans' mistrust of the biomedical community and other factors (e.g., racism, religious beliefs, access to medical care), they are also less likely to donate their biospecimens (e.g., blood) or agree to an autopsy for research [34-39]. Using a national survey completed by 249 Blacks/African Americans and 492 Whites from six U.S. cities, Minniefield et al. found that Blacks/African Americans had a lower total prevalence (63\%) of support for organ donation compared to Whites (90\%) [39]. More specific to brain donation for clinical research, using a survey completed by 49 Blacks/African Americans and 184 Whites recruited from an $\mathrm{AD}$ registry, Jefferson et al. found that only $49 \%$ of Blacks/African Americans compared to $75 \%$ of Whites would agree to brain donation for research $(p>0.001)$ [37]. Therefore, in order to increase Blacks/African American participation, several U.S. Alzheimer's Disease Centers (ADCs) responsible for conducting large-scale longitudinal human studies focused on dementia in elderly individuals, do not require Blacks/African Americans to agree to a brain donation upon enrolling into research studies, while they do require brain donation for White participants [40]. This recruitment strategy can potentially lead to increased autopsy-recruitment 
bias and limited generalizability of results. Such limitations must be adequately accounted for in analyses and discussed in research articles when reporting on Blacks/African Americans in ADC studies.

\section{CHALLENGES IN STUDYING AND COMPARING CLINICAL- NEUROPATHOLOGICAL VARIABLES BETWEEN BLACK/AFRICAN AMERICANS AND WHITE AMERICANS}

In studying the epidemiology of $\mathrm{AD}$ and related diseases while comparing Blacks/African Americans to Whites, some pitfalls become apparent: 1) lack of clarity in the operationalization and/or definition of race, 2) using race as a proxy for genetics, 3) failure to account for socio-environmental factors (e.g., socioeconomic status, access to healthcare), 4) lack of autopsy validation, and 5) lack of racial/ethnic and scientific diversity within research teams.

Using race as a variable in biomedical research is deceptively challenging, due to its vague definition, social implications, confounding factors, and potential for misinterpretation of results [41-43]. The historically evolving definitions of race (skin color, along with other physical and "ancestral" factors) have been discussed by Tishkoff et al., Guthrie, and Williams et al. [44-46]. Within these definitions, it is important to note the lack of clarity and consensusbased implications of the term "race" across various fields of study [41, 45, 47-49]. It has been noted that historic viewpoints of the biological construct of race were not grounded in firm scientific discovery $[45,49,50]$ but based on early 19th/20th century racist scientific studies, such as comparing "physiognomy" of Blacks/African Americans and Whites [15, 41, 45, 46, 51]. It has now been wellestablished that race is, in many senses, a social construct with categories that change over time due to social policy, cultural beliefs, and political practices [47-49]. Therefore, some scholars have suggested that race/ethnicity not be used as a proxy for socioenvironmental factors, but deconstructed into specific indictors such as region, language, education, economic level, and access to health care [52-54].

An important consideration is the relationship between race and genetics: variability in genomic phenomena between racial categories and variation of ancestral genetic markers within and between racial groups. Sometimes, there can be more genetic variation among individuals within the same racial category than between individuals from different racial categories [55-57]. Using genetic information on 5,269 Blacks/African Americans, 8,663 Latinos, and 148,780 Whites from 23 and Me, Bryc et al. [56] found that Blacks/African Americans living in different parts of the U.S. showed varying frequencies of genetic "African" ancestral markers. For example, a self-described "Black/African-American" living in the South had more "African" ancestral gene markers compared to "Blacks/African-Americans" living in the Northeast, Midwest, the Pacific Northwest, and California [56]. Moreover, selfidentified "Blacks/African-Americans" living in the West and Southwest had higher frequencies of "Native American" ancestral gene markers compared to "Blacks/African-Americans" living in other parts of the U.S. [56]. Thus, according to this sample, self-identified "Black/African-Americans" across the U.S. have varying proportions of "African" ancestral genetic markers [56]. Similar results of yarying "African" ancestral genetic markers in Blacks/African Americans were found by Sinha et al. In a cohort consisting of individuals living in Cleveland, OH [58]. In a 2003 New England Journal of Medicine article, Cooper et al. explains that Blacks/African Americans are assumed to be predisposed genetically to disease gene(s) even when genetic evidence is lacking, and the over-emphasis of genetics may support biases that further marginalize Blacks/African Americans [59].

Evidence from these papers indicates that race is not a dependable proxy for genetics given the sample-to-sample variation of ancestral genetic backgrounds among individuals within the same category operationalized by self-identification. Further, since many confounders (see below) apply, there is a serious risk of errantly associating a relatively "racespecific" genetic marker with a trait, when it actually is attributable to a regional or social factor. Continuing to use race as a proxy for genetic factors has the potential for detrimental political, social, and medical outcomes as a result of the over-simplification of results based on genetics, including medical stigmatization, racialization, genetic determinism, discrimination, and missed/delayed diagnoses [42, 44, 48, 59, 60].

To discuss race-related differences, environmental variables should be collected and accounted for before attributing and discussing genetics as a causal 
factor. There are many sources of bias and confounders [61]. Associations with race are potentially confounded by socioeconomic status (SES) variables including income level, education, and access to medical care [61-63]. In 2012, the U.S. Census Bureau reported that the median income for Black/African American households was \$33,321 compared to $\$ 57,009$ for White households [64]. In the same 2012 report, the percentage of Black/African American individuals living in poverty was $27.2 \%$ compared to $9.7 \%$ of White individuals [64]. In 2015, the Centers for Disease Control and Prevention (CDC) conducted a health interview survey that showed that $14.5 \%$ of Black/African American individuals were uninsured compared to $8.8 \%$ of White individuals [65]. The CDC reported that Black/African American individuals received worse care than White individuals for about $40 \%$ of health quality measures [65]. Many SES variables, socio-environmental exposures, and medical care variables (access, utilization, and discrimination) have been shown to contribute to adverse health outcomes [41, 61, 66, 67]. In our opinion, neuroscientists should not only adjust for these variables, but try to specifically identify the factors that contribute to dementia disparities in order to provide appropriate interven tions.

Examples are appearing in the literature that reveal interactions between SES (particularly poverty) and racial-ethnic factors [68-71], resulting in health disparities that can, in turn, influence interpretations of clinical and neuropathological associations. For example, Glymour et al. found that childhood and adult social conditions nearly entirely attenuated the association between race and stroke risk in a study population of 3,019 Blacks/African Americans and 17,642 Whites [72]. Waldstein et al., found significant interactions between race and SES composite scores when predicting radiographically-detected white matter lesions in a study population of 85 Blacks/African Americans and 62 White Americans [68]. In a study of 1,019 Blacks/African Americans and 1,438 White Americans, Yaffe et al. observed that the incident dementia hazard ratio was greatly reduced and no longer significant when SES was added to the statistical model [71].

The results of these studies strongly support the notion that genetically determinable mechanisms are highly unlikely to entirely account for the higher risk of dementia observed in Blacks/African Americans compared to Whites. Therefore, it is necessary to include SES variables in analyses when studying dementia outcomes among Blacks/African Americans. Failure to do so can result in misinterpretation of data as to the root causes of dementia outcomes within racial/ethnic groups. Notably, since 1994, NIH guidelines have specifically called for researchers to account for socioeconomic variables such as occupation, education, and income among human subjects [61].

The importance of autopsy-based (neuropathological) data in $\mathrm{AD}$ and related dementias has also become increasingly clear. For example, we highlight that both dementia and type II diabetes (T2D) are prevalent in Blacks/African Americans [72]. It is notable that data from different research centers have consistently reported that T2D is a risk factor for AD-type dementia in the chinical (no autopsy) context. By contrast, studies with a single added study design element - an autopsy-have shown the opposite result: $\mathrm{T} 2 \mathrm{D}$ is not a risk factor for AD pathology [73-75]. Instead, the autopsies reveal that the clinical diagnosis of $\mathrm{AD}$ was not completely accurate, and that T2D appears to exert its impact through a different (potentially additive when comorbid) disorder. cerebrovascular disease characterized by small and medium-sized blood vessel pathology [73]. Thus, a more vulnerable population may be underserved due to a clinical over-diagnosis of $\mathrm{AD}$ and an underappreciation of T2D-related cognitive impairment. This is all the more topical since therapies aimed at diabetes, blood pressure, and cholesterol may exert an impact on cerebrovascular pathology, but not yet $\mathrm{AD}$ itself.

Improving the representation of Blacks/African Americans across research and clinical disciplines will also enable improved research outcomes for ADC research teams. According to the 2010 U.S. Census Bureau report, Blacks/African Americans make up $12.6 \%$ of the U.S. population [12]. However, Blacks/African Americans make up only $~ 3.6 \%$ of biomedical research faculty, $\sim 4.1 \%$ of physicians, and $\sim 5.9 \%$ of social scientist faculty within the United States [76-78]. Several published studies have provided evidence that diversity of thought and identity among scientists enhances the quality and output of research collaborations, which makes for "better science" [79-81]. For example, Campbell et al. reported that gender-heterogeneous authorship teams received $34 \%$ more citations than publications produced by gender-uniform authorship teams [80]. 


\section{ADDRESSING THE PROBLEM: CONSIDERATIONS FOR THE FIELD}

It is appropriate that all populations within the U.S. be represented in biomedical research studies. In formulating hypotheses and conceptualizing study designs, the ultimate goal should be to improve the health and well-being of the target population [82]. In analyzing data within and across racial/ ethnic groups, we encourage neuroscientists to strive for better science by shifting the paradigm away from interpreting clinical/neuropathological results based on the framework of biologic determination to understanding and incorporating both biological and socio-environmental factors known to affect health outcomes. Therefore, Blacks/African Americans should be encouraged and included in biomedical research for the sole purpose of improving their health outcomes, not simply to identify a health disparity. With this paradigm shift in mind, if one is going to embark on this field of investigation, it is necessary to understand and attempt to account for the anthropological, psychological, sociological, political, biological, and cultural associations/causations attributing to health outcomes in Blacks/African Americans. In Table 1, we have provided some points of considerations for scientists embarking on this type of investigation. It is important to note that Table 1 contents are not exhaustive but a starting point for discussion.

\section{Cultural competency when interpreting research findings}

Alongside adding new variables, we suggest that scientists provide a rationale for their research question and provide adequate discussion of research findings (see Table 1). There should be justification for studying "differences" between racial categories $[47,83]$, information on categorization of study population (e.g., skin color, self-report) [42], analyses and discussions of socio-political factors that can contribute to research findings [24, 42], and explanation of the social, biological, and medical implications of misinterpretation and misrepresentation of data within their manuscript [47]. We encourage neuroscientists to solicit expert advice from anthropologists, sociologists, psychologists, African American community leaders, and other individuals who can provide contextual information on contributing factors to health outcomes. Ideally, these individuals can serve as co-authors on clinical-neuropathological manuscripts as suggested by Foster et al. who recommends publishing in cross-discipline journals [47].

Topical questions and recommendations for a study related to dementia in African Americans

\section{Experimental Design:}

i) How to choose and sample the African American population to study?

ii) What is the original hypothesis? If it involves studying "differences," are the strata sufficiently large to allow for adequate power for the detection of effect modification

iii) What are potential confounders that must be included? How might they affect your hypothesis and experimental design?

iv) How do health disparities in marginalized groups affect participation in the study and potentially the outcomes? Because "refusers" do not actually join the studies, how can potential differences or effects be estimated?

v) What is the justification for studying African Americans? What is the justification for excluding others groups (i.e., multi-racial individuals)

vi) How does composition of the research team affect results?

vii) How does this study contribute to helping underserved populations?

Methods:

i) Establish population stratified sampling methods, possibly similar to those used in cancer registries

ii) Enroll numbers of African Americans to have sufficient power and precision to address the associations under consideration

iii) How was the comparison group(s) chosen? How was the reference group chosen?

iv) How were the individuals recruited in the study? Was there a difference in recruited strategies for individuals from different racial categories?

v) How was data on racial category assigned and collected? (i.e., self-report)

Data collection:

i) SES variables (income, education, occupation, zip code, etc.)

ii) Exposures - social, other environmental

iii) Ancestry (i.e., country of birth, parent's place of birth)

iv) Medical care (insurance status, primary care physician, utilization)

v) Impact of worker collecting the data on the results

Discussion:

i) Implication of results, consequences for misinterpretation

ii) Limitations of study (recruitment bias, autopsy bias, investigator bias) 


\section{Recruitment of research participants}

In terms of context-specific issues, there is a lack of Black/African American representation in clinical-neuropathological datasets. Many articles have published goals and strategies for recruiting Blacks/African Americans and other marginalized groups into clinical studies-one major goal discussed in these articles is to build long-term trust within the Black/African American community [35, 40, 84]. Some recommendations for building trust are as follows: 1) publicly acknowledging the historical mistreatment of Blacks/African Americans in biomedical research $[24,36,83-85], 2)$ adequately explaining the consent process $[24,36,86]$, and protections in place to prevent mistreatment, 3) engaging in ongoing Q\&A discussions with the community [24, 30, 40, 84, 85, 87, 88], and 4) creating relationships that include patients, caregivers, healthcare providers, community leaders, researchers, and study coordinators [89]. Secondly, ADCs should actively enroll Blacks/African Americans, attach specific research questions, and perform power analyses so that it can be ensured that comparisons among individuals from different racial/ethnic groups will be valid. At present, some research centers enroll a percentage consistent with the surrounding geographic area (as the ADC) but that often just satisfies the "inclusion table" and the group is too small to perform any meaningful comparisons or analyses [ 90$]$.

We believe that by implementing some of these strategies, it can help to improve recruitment of Blacks/Africans Americans across research institutions. Moreover, it can help to provide neuroscientists with appropriate sample sizes in order to understand dementia progression in Blacks/African Americans. In turn, it has the potential to lead to improved medical and societal solutions decreasing dementia within the Black/African American population.

\section{Data and brain tissue collection}

In addition to building trust, we suggest that neuroscientists collect potentially confounding variables to include in data analyses (see Table 1). Some of these variables include income level, education, zip code, nativity, health insurance status, income level, primary care physician availability, and employment status [42]. The addition of these variables would aid neuroscientists in improving the understanding and analysis of clinical-neuropathological findings in Black/African Americans.
An additional point relates to the importance of autopsy-based confirmation of medical diagnoses. Autopsy-based neuropathological diagnoses are central to $\mathrm{AD}$ research in general, but may be all the more important in a historically underserved population where clinical and social factors may track differently than among the populations that have traditionally been included in clinical studies. In order to improve brain donation from Blacks/African Americans, we suggest that recruitment strategies incorporate education on the brain donation procedure and protection of human subjects.

\section{Recruiting and retaining a diverse biomedical research workforce}

It is important to have a culturally diverse group of experts included in the research team [36, 84, 87]. One long-term strategy for ADCs can be to increase African American representation among clinicians, scientists, epidemiologists, biostatisticians, and study coordinators to aid in experimental design and data analysis of $\mathrm{AD}$ and related dementias within the Black/African American population. Some strategies include effective career mentoring [91, 92], addressing unconscious bias and stereotype threat [77], and implementing pipeline and career development programs [93].

\section{CONCLUSION}

Studying $\mathrm{AD}$ and related dementias within the Black/African American population is a complex task due to the historical, cultural, and political factors that play a role in Black/African American participation in clinical studies. This commentary is not an exhaustive list of challenges and considerations, but, instead, aims to help move the discussion in the right direction. Moreover, this information can be applied to other underserved populations worldwide. Dementia is a devastating and multi-faceted clinical syndrome. We hope that dementia research centers can improve their recruitment strategies, recognize the subpopulation-specific challenges and opportunities, and incorporate more of the relevant data. Neuroscientists can create multi-disciplinary teams focused on understanding dementia in Black/African Americans and other marginalized groups, wary of the fact that research has the potential to do harm as well as good. 


\section{ACKNOWLEDGMENTS}

Corresponding authors Eseosa Ighodaro and Peter Nelson, $\mathrm{MD}, \mathrm{PhD}$ take responsibility for the integrity of this article. This work was supported by the following National Institute of Health grants: F30 NS090 714-01A1; P30 AG028383, R01 AG038651, R01 AG042419, T32 AG000242, K25 AG043546.

Authors' disclosures available online (http://j-alz. com/manuscript-disclosures/17-0242r1).

\section{REFERENCES}

[1] Tang MX, Cross P, Andrews H, Jacobs DM, Small S, Bell K, Merchant C, Lantigua R, Costa R, Stern Y, Mayeux R (2001) Incidence of $\mathrm{AD}$ in African-Americans, Caribbean Hispanics, and Caucasians in northern Manhattan. Neurology 56, 49-56.

[2] Tang MX, Stern Y, Marder K, Bell K, Gurland B, Lantigua R, Andrews H, Feng L, Tycko B, Mayeux R (1998) The APOE-epsilon4 allele and the risk of Alzheimer disease among African Americans, whites, and Hispanics. JAMA 279, 751-755.

[3] Green RC, Cupples LA, Go R, Benke KS, Edeki T, Griffith PA, Williams M, Hipps Y, Graff-Radford N, Bachman D, Farrer LA (2002) Risk of dementia among white and African American relatives of patients with Alzheimer disease. JAMA 287, 329-336.

[4] Graff-Radford NR, Besser LM, Crook JE, Kukull WA Dickson DW (2016) Neuropathologic differences by race from the National Alzheimer's Coordinating Center. Alzheimers Dement 12, 669-677.

[5] Barnes LL, Leurgans S, Aggarwal NT, Shah RC, Arvanitakis Z, James BD, Buchman AS, Bennett DA, Schneider JA (2015) Mixed pathology is more likely in black than white decedents with Alzheimer dementia. Neurology 85, 528-534.

[6] Riudavets MA, Rubio A, Cox C, Rudow G, Fowler D, Troncoso JC (2006) The prevalence of Alzheimer neuropathologic lesions is similar in blacks and whites. J Neuropathol Exp Neurol 65, 1143-1148.

[7] Sandberg G, Stewart W, Smialek J, Troncoso JC (2001) The prevalence of the neuropathological lesions of Alzheimer's disease is independent of race and gender. Neurobiol Aging 22, 169-175.

[8] Miller FD, Hicks SP, D'Amato CJ, Landis JR (1984) A descriptive study of neuritic plaques and neurofibrillary tangles in an autopsy population. Am J Epidemiol 120, 331-341.

[9] Wilkins CH, Grant EA, Schmitt SE, McKeel DW, Morris JC (2006) The neuropathology of Alzheimer disease in African American and white individuals. Arch Neurol 63, 87-90.

[10] de la Monte SM, Hutchins GM, Moore GW (1989) Racial differences in the etiology of dementia and frequency of Alzheimer lesions in the brain. J Natl Med Assoc 81, 644652.

[11] (2015) HHS Action Plan to Reduce Racial and Ethnic Health Disparities Implementation Progress Report. U.S. Dept. of Health and Human Services, Office of the Secretary, Office of the Assistant Secretary for Planning and Evaluation and Office of Minority Health, Washington, DC.
[12] (2010) 2010 Census of Population. U.S. Census Bureau, Population Estimates Program (PEP). Available from: https://www.census.gov/quickfacts/

[13] Savitt TL (1982) The use of blacks for medical experimentation and demonstration in the Old South. J South Hist 48, 331-348.

[14] Goodson MG (2003) Enslaved Africans and doctors in South Carolina. J Natl Med Assoc 95, 225-233.

[15] Washington HA (2006) Medical Apartheid: The Dark History of Medical Experimentation on Black Americans from Colonial Times to the Present, Anchor Books, New York.

[16] Byrd WM, Clayton LA (2001) Race, medicine, and health care in the United States: A historical survey. J Natl Med Assoc 93, 11s-34s.

[17] Garrod JZ (2006) A brave old world: An analysis of scientific racism and BiDil. Mcgill J Med 9, 54-60.

[18] Savitt TL (2005) Black health on the plantation: Owners, the enslaved, and physicians. OAH Mag Hist 19 , 14-16.

[19] Jones WF (1854) On the utility of the applications of hot water to the spine in the treatment of typhoid pneumonia. Virginia Med Surg J 3, 108-110.

[20] Randall VR (2006) Slavery, segregation and racism: Trusting the health care system ain't always easy. In Dying While Black, Seven Principle Press, Dayton, OH, pp. 117-136.

[21] Harden JMB (1846) Some experiments to determine the relative areas of the trunks and branches of arteries. South Med Surg J 2, 330-333.

Ojanuga D (1993) The medical ethics of the "father of gynaecology', Dr J Marion Sims. J Med Ethics 19, 28-31.

Axelsen DE (1985) Women as victims of medical experimentation: J. Marion Sims' surgery on slave women, 1845-1850. Sage 2, 10.

[24] Corbie-Smith G (1999) The continuing legacy of the Tuskegee Syphilis Study: Considerations for clinical investigation. Am J Med Sci 317, 5-8.

[25] King PA (1992) Twenty years after. The legacy of the Tuskegee Syphilis Study. The dangers of difference. Hastings Cent Rep 22, 35-38.

[26] Boyd MF, Kitchen SF (1937) Observations on induced falciparum. Am J Trop Med 17, 213-235.

[27] Katz A (1996) Prisoners volunteer to save lives. Philadelphia Bulletin, p. 1, February 27, 1996.

[28] Hornblum AM (1998) Acers of Skin: Human Experiments at Holmesburg Prison, Routledge, New York.

[29] Buchanan DR, Miller FG (2006) Justice and fairness in the Kennedy Krieger Institute lead paint study: The ethics of public health research on less expensive, less effective interventions. Am J Public Health 96, 781-787.

[30] Corbie-Smith G, Thomas SB, St George DM (2002) Distrust, race, and research. Arch Intern Med 162, 2458-2463.

[31] Hughes TB, Varma VR, Pettigrew C, Albert MS (2017) African Americans and clinical research: Evidence concerning barriers and facilitators to participation and recruitment recommendations. Gerontologist 57, 348-358.

[32] Braunstein JB, Sherber NS, Schulman SP, Ding EL, Powe NR (2008) Race, medical researcher distrust, perceived harm, and willingness to participate in cardiovascular prevention trials. Medicine (Baltimore) 87, 1-9.

[33] George S, Duran N, Norris K (2014) A systematic review of barriers and facilitators to minority research participation among African Americans, Latinos, Asian Americans, and Pacific Islanders. Am J Public Health 104, e16-31.

[34] Guadagnoli E, McNamara P, Evanisko MJ, Beasley C, Callender CO, Poretsky A (1999) The influence of race on 
approaching families for organ donation and their decision to donate. Am J Public Health 89, 244-247.

[35] Lambe S, Cantwell N, Islam F, Horvath K, Jefferson AL (2011) Perceptions, knowledge, incentives, and barriers of brain donation among African American elders enrolled in an Alzheimer's research program. Gerontologist 51, 28-38.

[36] Bonner GJ, Darkwa OK, Gorelick PB (2000) Autopsy recruitment program for African Americans. Alzheimer Dis Assoc Disord 14, 202-208.

[37] Jefferson AL, Lambe S, Cook E, Pimontel M, Palmisano J, Chaisson C (2011) Factors associated with African American and White elders' participation in a brain donation program. Alzheimer Dis Assoc Disord 25, 11-16.

[38] Siminoff LA, Burant CJ, Ibrahim SA (2006) Racial disparities in preferences and perceptions regarding organ donation. J Gen Intern Med 21, 995-1000.

[39] Minniefield WJ, Yang J, Muti P (2001) Differences in attitudes toward organ donation among African Americans and whites in the United States. J Natl Med Assoc 93, 372-379.

[40] Barnes LL, Shah RC, Aggarwal NT, Bennett DA, Schneider JA (2012) The Minority Aging Research Study: Ongoing efforts to obtain brain donation in African Americans without dementia. Curr Alzheimer Res 9, 734-745.

[41] Wyatt SB, Williams DR, Calvin R, Henderson FC, Walker ER, Winters K (2003) Racism and cardiovascular disease in African Americans. Am J Med Sci 325, 315-331.

[42] Wang VO, Sue S (2005) In the eye of the storm: Race and genomics in research and practice. Am Psychol 60, 37-45.

[43] Lin SS, Kelsey JL (2000) Use of race and ethnicity in epidemiologic research: Concepts, methodological issues, and suggestions for research. Epidemiol Rev 22, 187-202.

[44] Tishkoff SA, Kidd KK (2004) Implications of biogeography of human populations for 'race' and medicine. Nat Genet 36, S21-S27.

[45] Williams DR (1997) Race and health: Basic questions, emerging directions. Ann Epidemiol 7, 322-333.

[46] Guthrie RV (2003) Even The Rat Was White: A Historical View of Psychology, Peasron.

[47] Foster MW (2009) Looking for race in all the wrong places: Analyzing the lack of productivity in the ongoing debate about race and genetics. Hum Genet 126, 355-362.

[48] Foster MW, Sharp RR (2002) Race, ethnicity, and genomics: Social classifications as proxies of biological heterogeneity. Genome Res 12, 844-850.

[49] Brace CL (2002) The concept of race in physical anthropology. In Physical Anthropology Original Reading on Method and Practice, Peregrine PN, Ember CR, Ember MR, eds. Prentice Hall, p. 280.

[50] Montagu A (1962) The concept of race. Am Anthropol 64, 919-928.

[51] Gould SJ (1981) The Mismeasure of Man, W. W. Norton \& Company, New York.

[52] Dilworth-Anderson P, Hendrie HC, Manly JJ, Khachaturian AS, Fazio S (2008) Diagnosis and assessment of Alzheimer's disease in diverse populations. Alzheimers Dement 4, 305-309.

[53] Manly JJ (2005) Advantages and disadvantages of separate norms for African Americans. Clin Neuropsychol 19, 270275.

[54] Manly JJ (2006) Deconstructing race and ethnicity: Implications for measurement of health outcomes. Med Care 44, S10-S16.
[55] Tashiro CJ (2005) The meaning of race in healthcare and research-part 2. Current controversies and emerging research. Pediatr Nurs 31, 305-308.

[56] Bryc K, Durand EY, Macpherson JM, Reich D, Mountain JL (2015) The genetic ancestry of African Americans, Latinos, and European Americans across the United States. Am J Hum Genet 96, 37-53.

[57] Bamshad MJ, Olson SE (2003) Does race exist? Sci Am 289 , 78-85.

[58] Sinha M, Larkin EK, Elston RC, Redline S (2006) Selfreported race and genetic admixture. $N$ Engl J Med 354, 421-422.

[59] Cooper RS, Kaufman JS, Ward R (2003) Race and genomics. N Engl J Med 348, 1166-1170.

[60] Lee SS (2005) Racializing drug design: Implications of pharmacogenomics for health disparities. Am J Public Health 95, 2133-2138.

[61] Bleich SN, Jarlenski MP, Bell CN, LaVeist TA (2012) Health inequalities: Trends, progress, and policy. Аnпи Rev Public Health 33, 7-40.

[62] Kawachi I, Daniels N, Robinson DE (2005) Health disparities by race and class: Why both matter. Health Aff (Millwood) 24, 343-352.

[63] Mayberry RM, Mili, F., Ofili, E. (2002) Race and ethnic differences in access to medical care. In Race, Ethnicity, and Health, LaVeist TA, ed. Jossey-Bass, A Wiley Imprint, San Francisco, CA, p. 701.

164] DeNavas-Walt C, Proctor BD, Smith JC (2013) Income, Poverty, and Health Insurance Coverage in the United States: 2012. U.S. Census Bureau, Government Printing Office, Washington, DC.

[65] Ward BW, Schiller JS, Freeman G, Clarke TC (2015) Early release of selected estimates based on data from the January-June 2015 National Health Interview Survey. National Center for Health Statistics. Available from: http:// www.cdc.gov/nchs/nhis.htm

[66] Williams DR, Collins C (2001) Racial residential segregation: A fundamental cause of racial disparities in health. Public Health Rep 116, 404-416.

[67] (2006) Health disparities: Concepts, measurements, and understanding. In Examining the Health Disparities Research Plan of the National Institutes of Health: Unfinished Business, Institute of Medicine; Board on Health Sciences Policy; Thomson GE, Mitchell F, Williams MB, eds. National Academies Press, Washington, DC, pp. 21-33.

[68] Waldstein SR, Dore GA, Davatzikos C, Katzel LI, Gullapalli R, Seliger SL, Kouo T, Rosenberger WF, Erus G, Evans MK, Zonderman AB (2017) Differential associations of socioeconomic status with global brain volumes and white matter lesions in African American and white adults: The HANDLS SCAN Study. Psychosom Med 79, 327-335.

[69] Dore GA, Waldstein SR, Evans MK, Zonderman AB (2015) Associations between diabetes and cognitive function in socioeconomically diverse African American and white men and women. Psychosom Med 77, 643-652.

[70] Glymour MM, Avendano M, Haas S, Berkman LF (2008) Lifecourse social conditions and racial disparities in incidence of first stroke. Ann Epidemiol 18, 904-912.

[71] Yaffe K, Falvey C, Harris TB, Newman A, Satterfield S, Koster A, Ayonayon H, Simonsick E (2013) Effect of socioeconomic disparities on incidence of dementia among biracial older adults: Prospective study. BMJ 347, f7051. 
[72] Center for Disease Control and Prevention (2014) National Diabetes Statistics Report: Estimates of Diabetes and Its Burden in the United States. U.S. Department of Health and Human Services, Atlanta, GA.

[73] Abner EL, Nelson PT, Kryscio RJ, Schmitt FA, Fardo DW, Woltjer RL, Cairns NJ, Yu L, Dodge HH, Xiong C, Masaki $\mathrm{K}$, Tyas SL, Bennett DA, Schneider JA, Arvanitakis Z (2016) Diabetes is associated with cerebrovascular but not Alzheimer's disease neuropathology. Alzheimers Dement 12, 882-889.

[74] Nelson PT, Abner EL, Schmitt FA, Kryscio RJ, Jicha GA, Smith CD, Davis DG, Poduska JW, Patel E, Mendiondo MS, Markesbery WR (2010) Modeling the association between 43 different clinical and pathological variables and the severity of cognitive impairment in a large autopsy cohort of elderly persons. Brain Pathol 20, 66-79.

[75] Nelson PT, Smith CD, Abner EA, Schmitt FA, Scheff SW, Davis GJ, Keller JN, Jicha GA, Davis D, Wang-Xia W, Hartman A, Katz DG, Markesbery WR (2009) Human cerebral neuropathology of Type 2 diabetes mellitus. Biochim Biophys Acta 1792, 454-469.

[76] (2015) Women, Minorities, and Persons with Disabilities in Science and Engineering. National Science Foundation, National Center for Science and Engineering Statistics, Arlington, VA. Available from: http://www.nsf.gov/statist ics/wmpd/

[77] Valantine HA, Collins FS (2015) National Institutes of Health addresses the science of diversity. Proc Natl Acad Sci U S A 112, 12240-12242.

[78] (2014) Diversity in the Physician Workforce: Facts \& Figures 2014. Association of American Medical Colleges (AAMC), Washington, DC. Available from: http://aamc diversityfactsandfigures.org/about-this-report/

[79] Hong L, Page SE (2004) Groups of diverse problem solvers can outperform groups of high-ability problem solvers. Proc Natl Acad Sci U S A 101, 16385-16389.

[80] Campbell LG, Mehtani S, Dozier ME, Rinehart J (2013) Gender-heterogeneous working groups produce higher quality science. PLoS One 8, e79147.

[81] Freeman RB, Huang W (2014) Collaborating with people like me: Ethnic co-authorship within the US (No. w19905). Available from http://www.nber.org/papers/w19905

[82] Kittles R, Royal C (2003) The genetics of African Americans: Implications for disease gene mapping and identity. In Genetic Nature/culture: Anthropology and Science beyond the Two-Culture Divide, University of California Press, Berkeley, CA, p. 225.

[83] Dennis BP, Neese JB (2000) Recruitment and retention of African American elders into community-based research: Lessons learned. Arch Psychiatr Nurs 14, 3-11.
[84] Schnieders T, Danner DD, McGuire C, Reynolds F, Abner E (2013) Incentives and barriers to research participation and brain donation among African Americans. Am J Alzheimers Dis Other Demen 28, 485-490.

[85] Zaramo CE, Morton T, Yoo JW, Bowen GR, Modlin CS (2008) Culturally competent methods to promote organ donation rates among African-Americans using venues of the Bureau of Motor Vehicles. Transplant Proc 40, 10011004.

[86] Dunlop AL, Leroy ZC, Logue KM, Glanz K, Dunlop BW (2011) Preconsent education about research processes improved African Americans' willingness to participate in clinical research. J Clin Epidemiol 64, 872-877.

[87] Darnell KR, McGuire C, Danner DD (2011) African American participation in Alzheimer's disease research that includes brain donation. Am J Alzheimers Dis Other Demen 26, 469-476.

[88] Zhou Y, Elashoff D, Kremen S, Teng E, Karlawish J, Grill JD (2017) African Americans are less likely to enroll in preclinical Alzheimer's disease clinical trials. Alzheimers Dement (N Y) 3, 57-64.

[89] Gorelick PB, Harris Y, Burnett B, Bonecutter FJ (1998) The recruitment triangle: Reasons why African Americans enroll, refuse to enroll, or voluntarily withdraw from a clinical trial An interim report from the African-American Antiplatelet Stroke Prevention Study (AAASPS). J Natl Med Assoc 90, 141-145.

190] Whitfield KE, Allaire JC, Belue R, Edwards CL (2008) Are comparisons the answer to understanding behavioral aspects of aging in racial and ethnic groups? J Gerontol B Psychol Sci Soc Sci 63, P301-308.

91] Beecham GW, Hamilton K, Naj AC, Martin ER, Huentelman M, Myers AJ, Corneveaux JJ, Hardy J, Vonsattel JP, Younkin SG, Bennett DA, De Jager PL, Larson EB, Crane PK, Kamboh MI, Kofler JK, Mash DC, Duque L, Gilbert JR, Gwirtsman H, Buxbaum JD, Kramer P, Dickson DW, Farrer LA, Frosch MP, Ghetti B, Haines JL, Hyman BT, Kukull WA, Mayeux RP, Pericak-Vance MA, Schneider JA, Trojanowski JQ, Reiman EM, Schellenberg GD, Montine TJ (2014) Genome-wide association meta-analysis of neuropathologic features of Alzheimer's disease and related dementias. PLoS Genet 10, e1004606.

[92] Layton RL, Brandt PD, Freeman AM, Harrell JR, Hall JD, Sinche M (2016) Diversity exiting the academy: Influential factors for the career choice of well-represented and underrepresented minority scientists. CBE Life Sci Educ 15, pii: ar41.

[93] Rodriguez JE, Campbell KM, Mouratidis RW (2014) Where are the rest of us? Improving representation of minority faculty in academic medicine. South Med J 107, 739-744. 